\title{
Road Performance of Calcium Sulfate Whisker and Polyester Fiber Composite-Modified Asphalt Mixture
}

\author{
Xiushan Wang $(\mathbb{D}$, Bowen Dong, and Junjie Wang \\ Department of Building Engineering, Zhejiang Sci-Tech University, Hangzhou, Zhejiang 310018, China \\ Correspondence should be addressed to Xiushan Wang; wxs77777@163.com
}

Received 4 July 2020; Accepted 16 September 2020; Published 25 September 2020

Academic Editor: Victor M. Castaño

Copyright (c) 2020 Xiushan Wang et al. This is an open access article distributed under the Creative Commons Attribution License, which permits unrestricted use, distribution, and reproduction in any medium, provided the original work is properly cited.

In order to better improve the practical engineering problems such as rutting, cracking, pit, and groove in highway engineering, the stability and strength characteristics of calcium sulfate whisker and polyester fiber in asphalt mixture are evaluated based on the road performance test. In this experiment, three different methods of the calcium sulfate whisker content and three different polyester fiber content were used to determine the best asphalt aggregate ratio to prepare different modified asphalt mixture samples. Its high temperature stability, water stability, and low-temperature performance were tested. The results show that the composite modifier of calcium sulfate whisker and polyester fiber can significantly improve the strength stability of asphalt mixture and make its high temperature stability reach 2900.3 4230.7 Times/mm without reducing its low-temperature bending strength. The optimum content of calcium sulfate whisker is in the range of $2 \%_{0} \sim 2.5 \%$ and polyester fiber is in the range of $2 \%_{0} \sim$ $3 \%$. The rutting strength and Marshall stability reach the maximum.

\section{Introduction}

Asphalt is a kind of viscoelastic material, which is temperature-sensitive. It is easy to soften at high temperature and cause rutting. At low temperature, it is easy to make it brittle and cause cracks [1]. The high- and low-temperature performance of asphalt can be improved by SBR-TPS composite modification [2]. Through PPA-SBR modification, it can effectively enhance the high temperature antiaging performance of asphalt [3]. Through RET and SBS/SBR polymer compound modification, can effectively improve the high- and low-temperature performance of asphalt mixture and water stability [4].Therefore, the compositemodified asphalt mixture is favored for its high temperature stability, low-temperature bending performance, and other road performance $[5,6]$.

It is an important technology that the mixture and modifier are fully mixed to form a higher strength modified asphalt mixture in asphalt pavement treatment. The commonly used modifiers mainly include fiber, resin, and polymer. Nowadays, a large number of research studies on fiber-modified asphalt mixture show that fiber plays a significant role in strengthening asphalt mixture by melting and dispersing. In order to reduce the strength loss of asphalt during transportation and construction, adding fiber into SMA mixture is an effective way [7]. Serfass and Samanos point out that adding fiber to the mixture can enhance the asphalt content and improve the moisture resistance, aging resistance, and fatigue cracking resistance of the mixture [8].Morova pointed out that the addition of $0.50 \%$ basalt fiber in hot mix asphalt concrete has a positive impact on the stability of the mixture [9].Wang and Gu pointed out that basalt fiber used in asphalt mastic has a good performance in strength, durability, and suitability in a large temperature range $[10,11]$.Liang found that polyester fiber $(\mathrm{PF})$ is a good oil absorption material, and its strong adsorption capacity will improve the asphalt aggregate ratio, enhance the cohesion between aggregates, play a role of reinforcement. Therefore, the phenomenon of stress concentration in the structure is alleviated, and then, the low-temperature performance of the mixture is improved [12]. Dong et al. pointed out that polyester fiber $(\mathrm{PF})$ can increase the thickness of the asphalt membrane by increasing the asphalt content of asphalt mixture, thus increasing the interface 
energy between asphalt and aggregate to improve the water stability of modified asphalt mixture [13].

Whisker is a kind of nanoshort fiber grown by highpurity single crystal. Because of its nearly complete crystal structure, it has high strength, modulus, and elongation. For example, calcium sulfate whiskers (CSW) are anhydrous calcium sulfate fibrous crystals grown in the form of single crystals with gypsum as raw material under artificial control [14]. Zhang et al. found that adding whiskers to high modulus asphalt mixture can improve its high temperature stability [15]. Xing et al. found that whiskers can improve the high-temperature performance of asphalt [16]. Wang studied the influence of different content of CSW on the road performance of asphalt mixture and found that CSW can greatly improve the high-temperature performance of the mixture [17].

Referring to the abovementioned research, calcium sulfate whisker (CSW) and polyester fiber (PF) can improve the mixture performance at high and low temperature, respectively. If they are combined, it is hopeful to obtain asphalt mixture with good high- and low-temperature performance. At present, there is little research on the performance of CSW and PF composite asphalt mixture. In this subject, different contents of CSW and PET are added to the asphalt mixture at the same time. Through the road performance test method, the high temperature stability, water stability, and low-temperature performance of the composite modified asphalt mixture are studied. The influence of the CSW-PF composite modifier on the comprehensive road performance of the mixture under different proportion is tested. The engineering selection of modifier is of great significance.

\section{Materials and Methods}

\subsection{Materials}

2.1.1. Asphalt Binder. The base asphalt used for the test is 70\# A road asphalt, and the basic technical indexes are shown in Table 1.

2.1.2. Aggregate. The aggregates used in this study are all produced in Lanxi, Zhejiang Province, with $52 \%$ basalt as the coarse aggregate, $46 \%$ basalt rock debris as the fine aggregate, and $2 \%$ ordinary basalt mineral powder as the mineral powder. Aggregate material tests were carried out based on Code for aggregate test of Highway Engineering (JTG E422005), in order to obtain the physical and mechanical characteristics of the aggregate used in the mixtures. The aggregate properties are shown in Table 2.

2.1.3. Calcium Sulfate Whisker and Polyester Fiber. Calcium sulfate whisker (CSW) is an inorganic fibrous single-crystal material and produced from gypsum, calcium saltphosphogypsum, and flue gas desulfurization gypsum as raw materials [18]. CSW has the advantages of good compatibility, high strength, and high temperature resistance. It is a new environmental protection material. Compared with polymer modification, polyester fiber (PF) can effectively control the expansion of temperature shrinkage cracks in the asphalt pavement, reduce rut deformation and fatigue damage, and significantly improve the service life of the asphalt pavement. In this study, calcium sulfate whisker and polyester fiber were used to modify the mixture [19]. The properties of calcium sulfate whisker and polyester fiber are shown in Table 3 and 4.

\subsection{Methods}

2.2.1. Ratio Design. In order to compare the different effects of polyester fiber and calcium sulfate whisker on the stability of asphalt mixture, the content of polyester fiber and calcium sulfate whisker used in this study are $1 \%, 2 \%$, and $3 \%$ and $1.5 \%$, $2 \%$, and $2.5 \%$ (mass percentage of asphalt mixture), respectively. Due to the oil absorption of polyester fiber, the bitumie-aggregate ratio of the mixture will be different with the amount of modifier added. According to the calculation method of the bitumie-aggregate ratio specified in the Technical Code for Construction of Highway Asphalt Pavement (JTG F40-2004), the Marshall test is used to determine the optimum bitumie-aggregate ratio of mixture under different modifier addition amounts. The optimum bitumie-aggregate ratio with different modifiers is given in Table 5.

Table 5 shows the optimum bitumie-aggregate ratio of composite-modified asphalt mixture with CSW, and PF is higher than that of matrix asphalt mixture. When the content of CSW is fixed, with the increase of the content of polyester fiber, the bitumie-aggregate ratio will also increase, which shows that polyester fiber has an oil absorption property. When the content of CSW is $1.5 \%$, the content of $\mathrm{PF}$ increases from $1 \%$ to $3 \%$, and the bitumie-aggregate ratio increases from 5 to 5.5 , which is $10 \%$ higher than that of matrix asphalt mixture, When the content of CSW is $2 \%$, the bitumie-aggregate ratio increases from 5.1 to 5.5 , which is $11.2 \%$ higher than that of matrix asphalt mixture, and the growth rate is basically the same. Because polyester fiber is insoluble in asphalt, when the content of fiber increases, asphalt needs to wrap all fibers, which leads to the increase of the contact surface and content of the asphalt binder and aggregate.

2.2.2. Experimental Method. In order to study the influence of fiber and whisker on the high-temperature stability, water stability, and low-temperature crack resistance of matrix asphalt mixture, according to the Test Code for Asphalt and Asphalt Mixture of Highway Engineering (JTG E20-2011), respectively, a rut tester, asphalt mixture Marshall tester, and universal material tester are used to carry out the rutting test, freeze-thaw splitting test, immersion Marshall test, and bending test for the modified asphalt mixture test. The detailed test procedure is as follows:

(1) Rutting test: the modified asphalt mixture is made into a plate specimen with a length of $300 \mathrm{~mm}$, a width of $300 \mathrm{~mm}$, and a thickness of $75 \mathrm{~mm}$ 
TABLE 1: Technical indexes of 70\# A road asphalt.

\begin{tabular}{lcc}
\hline Parameter & Results & Standard in China (JTG E20-2011) \\
\hline Penetration $(0.1 \mathrm{~mm})$ & 66 & $60-80$ \\
Softening point $\left({ }^{\circ} \mathrm{C}\right)$ & 48 & $\geq 46$ \\
$15^{\circ} \mathrm{C}$ ductility $(\mathrm{cm})$ & $>150$ & $\geq 100$ \\
$10^{\circ} \mathrm{C}$ ductility $(\mathrm{cm})$ & 32 & $\geq 20$ \\
Wax content $(\%)$ & 1.8 & $\leq 2.2$ \\
Flash point $\left({ }^{\circ} \mathrm{C}\right)$ & 342 & $\geq 260$ \\
Solubility (trichloroethylene) $(\%)$ & 99.96 & $\geq 99.5$ \\
\hline After subjecting to aging in a thin-film oven (TFOT) $\left(163^{\circ} \mathrm{C} 5 \mathrm{~h}\right)$ & 0.2 & $\leq 0.6$ \\
Loss in weigh $(\%)$ & 68 & $\geq 65$ \\
Penetration ratio $(\%)$ & 7 & $\geq 6$ \\
Ductility $(\mathrm{cm})\left(5 \mathrm{~cm} / \mathrm{min}, 10^{\circ} \mathrm{C}\right)$ & \\
\hline
\end{tabular}

Table 2: Properties of the aggregate used in the study.

\begin{tabular}{|c|c|c|c|}
\hline Sieve diameters & Properties & Results & Standard in China (JTG E42-2005) \\
\hline \multirow{3}{*}{ Mineral powder } & Specific gravity $\left(\mathrm{g} / \mathrm{cm}^{3}\right)$ & 2.682 & $\geq 2.6$ \\
\hline & Hydrophilic coefficient & 0.7 & $<1$ \\
\hline & Plasticity index (\%) & 3.7 & $<4$ \\
\hline \multirow{4}{*}{$4.75-0.075 \mathrm{~mm}$} & Specific gravity $\left(\mathrm{g} / \mathrm{cm}^{3}\right)$ & 2.70 & $\geq 2.50$ \\
\hline & Firmness (\%) & 5 & $\leq 12$ \\
\hline & Sediment percentage $(\%)$ & 1.1 & $\leq 1.2$ \\
\hline & Sand equivalent (\%) & 64 & $\geq 60$ \\
\hline \multirow{3}{*}{$9.5-4.75 \mathrm{~mm}$} & Specific gravity $\left(\mathrm{g} / \mathrm{cm}^{3}\right)$ & 2.70 & $\geq 2.60$ \\
\hline & Water absorption (\%) & 1.79 & $\leq 2.0$ \\
\hline & Abrasion loss (\%) (Los Angeles) & 23 & $\leq 28$ \\
\hline \multirow{3}{*}{$16-9.5 \mathrm{~mm}$} & Specific gravity $\left(\mathrm{g} / \mathrm{cm}^{3}\right)$ & 2.68 & $\geq 2.60$ \\
\hline & Water absorption (\%) & 1.7 & $\leq 2.0$ \\
\hline & Abrasion loss (\%) (Los Angeles) & 20 & $\leq 28$ \\
\hline
\end{tabular}

TABle 3: The basic properties of CSW.

\begin{tabular}{lcccc}
\hline Project & Density $\left(\mathrm{g} \cdot \mathrm{cm}^{-3}\right)$ & Draw ratio & Tensile strength $(\mathrm{GPa})$ & Melting point $\left({ }^{\circ} \mathrm{C}\right)$ \\
\hline Test results & 2.69 & $10 \sim 60$ & 20.50 & 1450 \\
\hline
\end{tabular}

TABle 4: Basic properties of PF.

\begin{tabular}{lcccccc}
\hline Project & Length $(\mathrm{mm})$ & Diameter $(\mu \mathrm{m})$ & Gravity $\left(\mathrm{g} \cdot \mathrm{cm}^{3}\right)$ & Melting point $\left({ }^{\circ} \mathrm{C}\right)$ & Ignition point $\left({ }^{\circ} \mathrm{C}\right)$ & Tensile strength $(\mathrm{MPa})$ \\
\hline Test results & 3 & $10 \sim 25$ & 1.36 & 258 & 556 & $\geq 600$ \\
\hline
\end{tabular}

TABLE 5: Optimum bitumie-aggregate ratio with different modifiers.

\begin{tabular}{lccc}
\hline Samples name & Calcium sulfate whisker $(\%)$ & Polyester fiber $(\%)$ & Bitumie-aggregate ratio (\%) \\
\hline Control sample & 0 & 0 & 4.9 \\
C1.5P1 & 1.5 & 1 & 5 \\
C1.5P2 & 1.5 & 2 & 5.2 \\
C1.5P3 & 1.5 & 3 & 5.5 \\
C2P1 & 2 & 1 & 5.1 \\
C2P2 & 2 & 2 & 5.3 \\
C2P3 & 2 & 3 & 5.5 \\
C2.5P1 & 2.5 & 1 & 5.3 \\
C2.5P2 & 2.5 & 2 & 5.3 \\
C2.5P3 & 2.5 & 3 & 5.6 \\
\hline
\end{tabular}

C: calcium sulfate whisker; P: polyester fiber. 
according to the optimum bitumie-aggregate ratio of calcium sulfate whiskers and polyester fibers. All specimens and trial modes were cured for $6 \mathrm{~h}$ in a standard curing room at a temperature of $60^{\circ} \mathrm{C}$ and paste thermocouple thermometer. Then, a $0.7 \mathrm{MPa}$ pressure test wheel is used to load the modified asphalt mixture for $1 \mathrm{~h}$, and its deformation curve and loading temperature are recorded.

(2) Freeze-thaw splitting test: using the Marshall compaction method, the modified asphalt mixture was prepared into $\varphi 101.6 \times 63.5$ cylindrical specimens, 8 specimens were prepared per group, and the 8 specimens in each group were divided into two groups on average in the same time. Among them, the first group is stored at room temperature, and the second group is placed in a plastic bag containing $10 \mathrm{ml}$ of water after the water immersion test, sealed, and placed in a constant temperature refrigerator at $-18^{\circ} \mathrm{C}$ for $16 \mathrm{~h}$. Then, the specimens were immediately put in the $60^{\circ} \mathrm{C}$ constant temperature water tank for $24 \mathrm{~h}$. Finally, two sets of specimens were placed in a constant temperature water tank at $25^{\circ} \mathrm{C}$ for 2 hours, and then, the specimens were taken out, and the split test was carried out at a loading rate of $50 \mathrm{~mm} / \mathrm{min}$.

(3) Immersion Marshall test: using the Marshall compaction method, the modified asphalt mixture was prepared into $\varphi 101.6 \times 63.5$ cylindrical specimens; 4 specimens were prepared for each group and placed in a $60^{\circ} \mathrm{C}$ constant temperature water tank for 48 hours. The pressure and deformation curve were recorded using a Marshall stabilizer, and the loading rate was $50 \mathrm{~mm} / \mathrm{min}$.

(4) Bending test: according to the compound modifier of different proportions, a Prismatic trabecular with a length of $250 \mathrm{~mm}$, a width of $30 \mathrm{~mm}$, a height of $35 \mathrm{~mm}$, and a span of $200 \mathrm{~mm}$ was prepared. Then, it is kept in a constant temperature curing room for $45 \mathrm{~min}$ until $-15^{\circ} \mathrm{C}$, and the specimens are immediately taken out and placed symmetrically on the support. Using a universal testing machine to load the specimens and read their deflection result, the loading rate is $50 \mathrm{~mm} / \mathrm{min}$.

\section{Results and Discussion}

3.1. Stability Test in High Temperature. The results of rutting test dynamic stability are the main index to measure the high-temperature stability performance of asphalt mixture. The rutting test is carried out for the composite-modified asphalt mixture with different amounts of the modifier. The dynamic stability of three samples is tested for each group of performance. Figure 1 shows the results of the rutting test.

It can be seen from Figure 1 that the dynamic stability of composite-modified asphalt mixture is much higher than that of unmodified asphalt mixture. When the CSW content is $2.5 \%$ and the polyester fiber content is $2 \%$ (C2.5P2), the dynamic stability value of modified asphalt mixture is the highest (4230.7 times/mm), which is $92.2 \%$ higher than that of matrix asphalt mixture. After these values, a decrease was seen. When the content of polyester fiber is fixed, the dynamic stability will increase with the increase of the CSW content. For example, when the PF content is $2 \%$, the CSW content increases from $1.5 \%$ to $2.5 \%$ and the dynamic stability of asphalt mixture gradually increases from 3526.9 times $/ \mathrm{mm}$ to 4230.7 times $/ \mathrm{mm}$. It can be seen that CSW can effectively improve the high-temperature stability of asphalt mixture, mainly due to the network distribution of CSW in the aggregate. The more the whisker content added, the more the range of spatial network distribution, so as to improve the interaction between asphalt mixture and reduce the temperature sensitivity of asphalt mixture [15].When the content of CSW is fixed, taking $2 \%$ of CSW as an example, with the increase of the PF content from $1 \%$ o to $2 \%$, the dynamic stability of asphalt mixture increases from 3000.7 times $/ \mathrm{mm}$ to 3720.6 times $/ \mathrm{mm}$, which increased by $23 \%$ and reached the peak value, but the dynamic stability of PF above $2 \%$ begins to decrease to 3423.6 times $/ \mathrm{mm}$. The results show that when the amount of polyester fiber is moderate, the fiber is evenly dispersed in the asphalt mixture and plays a role of reinforcement. The dynamic stability of the asphalt mixture is improved and the high-temperature performance is improved. When the fiber content exceeds the optimum content, the asphalt mixture is not evenly dispersed and agglomerated, so the dynamic stability of the mixture will be reduced and the high-temperature performance will be reduced. The optimum content of polyester fiber is $2 \%$ o $3 \%$.

3.2. Water Stability Test. Water stability indicates the ability of asphalt mixture to resist water damage. In this paper, the freeze-thaw splitting test and immersion Marshall test are used to evaluate the water stability of asphalt mixture. The Freeze-thaw Splitting Strength Ratio (TSR) is used to evaluate the water stability of the mixture in the freeze-thaw splitting test. The Marshall residual stability is used to evaluate the water stability of asphalt mixture in the immersion Marshall test. Figure 2 shows the results of the water stability test.

From the test data in Figure 3, it can be seen that the TSR and residual stability ratio of CSW-PF composite-modified asphalt mixture are higher than those of unmodified asphalt mixture. It can be seen that CSW-PF composite modification can significantly improve the water stability of asphalt mixture. When the CSW content is $2.5 \%$ and PF content is $3 \%$, the TSR value $(83.7 \%)$ and residual stability ratio (91.2\%) reach the highest value, which is about 30\% higher than that of base asphalt mixture. When the PF content is fixed, the TSR value and immersion stability ratio increase at the same time with the increase of the CSW content, and the trend is basically the same, but the increase is small. For example, when the PF content is $3 \%$, the CSW content increases from $1.5 \%$ to $2.5 \%$, the TSR value of modified asphalt mixture increases from $80.7 \%$ to $83.7 \%$, about $3.7 \%$, and the residual stability ratio increases from $90.2 \%$ to $91.2 \%$, about $1.1 \%$. It can be seen that CSW can improve the water stability of asphalt mixture, but the effect of 


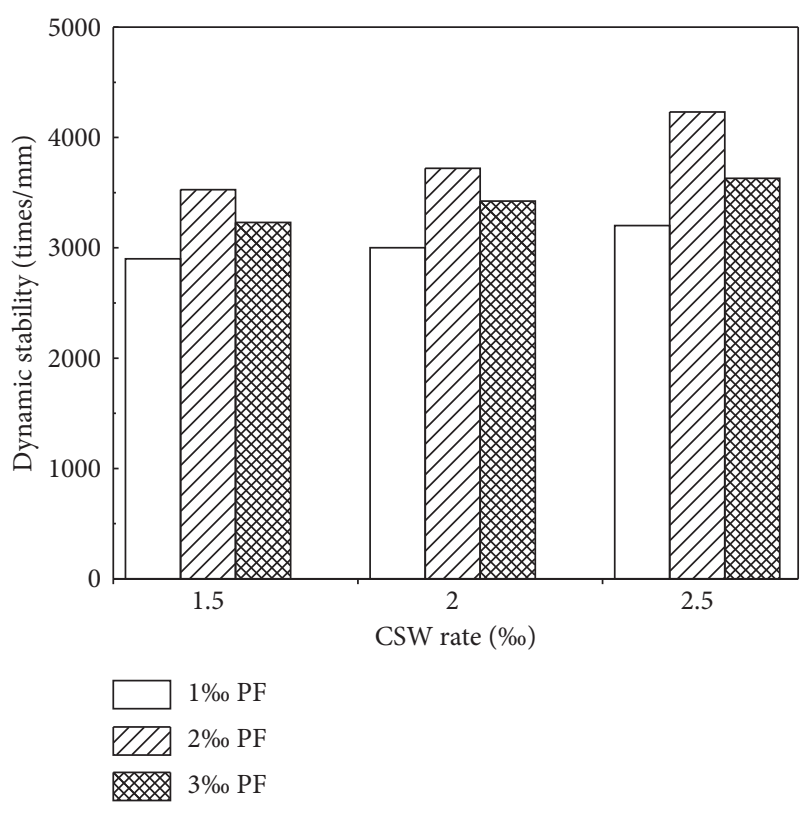

Figure 1: Comparison of dynamic stability values for different polyester fiber amounts and for certain calcium sulfate whisker rates.

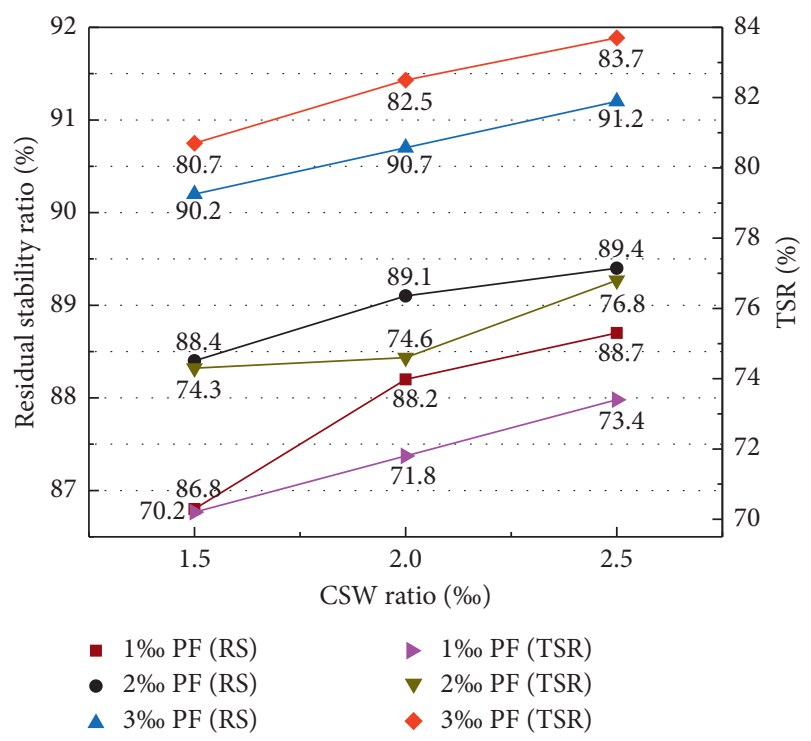

FIgURe 2: Water stability test results.

modification is not obvious. When the amount of CSW is fixed, with the increase of PF, the TSR value and residual stability ratio increase rapidly. For example, when the amount of CSW is $2.5 \%$, the PF content increases from $1 \%$ o to $3 \%$, the TSR value of asphalt mixture increases from $73.4 \%$ to $83.7 \%, 14 \%$, and the residual stability ratio increases from $88.7 \%$ to $91.2 \%, 2.8 \%$. It can be seen that the increase of the PF content has a significant effect on the TSR of asphalt mixture, but it does not significantly improve the residual stability. So, in conclusion, the effect of improving the water stability of asphalt mixture is not ideal because of the small amount of the CSW-PF modifier.
3.3. Bending Test in Low Temperature. The low-temperature bending test is a common test method to evaluate the lowtemperature crack resistance of asphalt mixture. At low temperature, the strength of asphalt mixture becomes higher and its deformation ability becomes weaker. The better the deformation resistance of asphalt mixture is, the better its lowtemperature performance is. The failure bending strain in the low-temperature bending test reflects the deformation ability of asphalt mixture well. Therefore, the low-temperature bending test is taken as the index to evaluate the low-temperature performance of asphalt mixture. The greater the bending strain, the better the low-temperature performance of asphalt mixture. Figure 3 shows the results of the bending test.

The results in Figure 3 show that the bending and tensile strain values of the composite-modified asphalt mixture are higher than that of the base asphalt mixture, which shows that csw-pf composite modification can effectively improve the low-temperature performance of the asphalt mixture. It can be seen from Figure 3(a) that when the PF content is constant, the proportion of CSW in asphalt becomes larger, and the maximum bending tensile strain increases first and, then, decreases. When the PF content is $3 \%$, the CSW content increases from $1.5 \%$ to $2 \%$ and the bending strain value increases from $2656.7 \mu \varepsilon$ to $2827.8 \mu \varepsilon$ and reaches a peak value, and then, when the CSW content increases from $2 \%$ to $2.5 \%$, the bending strain value decreases from $2827.8 \mu \varepsilon$ to $2435.2 \mu \varepsilon$. When the PF content is $1 \%$ and $2 \%$, the bending strain value changes with the change of the CSW content $3 \%$ is the same, increasing first and, then, decreasing. When the content of polyester fiber is the same, the bending strain value of the mixture with $2.5 \%$ CSW is less than that of the mixture with $1.5 \%$ CSW. Figure 3(b) shows that the maximum bending tensile strain increases with the increase of polyester fiber when the content of CSW is constant. When the content of CSW in asphalt is $1.5 \%$, the content of bending strain increases from $2311.7 \mu \varepsilon$ to $2656.7 \mu \varepsilon$, increasing by $14.9 \%$; when the content of CSW in asphalt is $2 \%$, the content of bending strain increases from $2349.7 \mu \varepsilon$ to $2827.8 \mu \varepsilon$, increasing by $20.3 \%$; when the content of CSW in asphalt is $2 \%$, the content of bending strain increases from $2349.7 \mu \varepsilon$ to $2827.8 \mu \varepsilon$, increasing by $20.3 \%$ at $2.5 \%$, and with the increase of the polyester fiber content, bending strain increased from $2260.7 \mu \varepsilon$ to $2435.2 \mu \varepsilon$, an increase of $7.7 \%$. Therefore, when the content of CSW is $2 \%$, the change of the polyester fiber content has the greatest influence on the low-temperature performance of asphalt mixture. When the content of CSW is $2.5 \%$, the increase of the bending strand has the smallest change with the increase of polyester fiber. It can be seen that PF can improve the low-temperature performance of asphalt mixture, and excessive CSW can reduce the low-temperature performance of asphalt mixture. When the CSW content is between 1.5\%o 2.0\%o, the composite-modified asphalt mixture has the best low-temperature performance. The reason is that the low-temperature ductility of asphalt mixture is affected by the low-temperature ductility of asphalt. Excessive CSW will reduce the low-temperature ductility of asphalt, so that the low-temperature performance of asphalt mixture will also be reduced. 


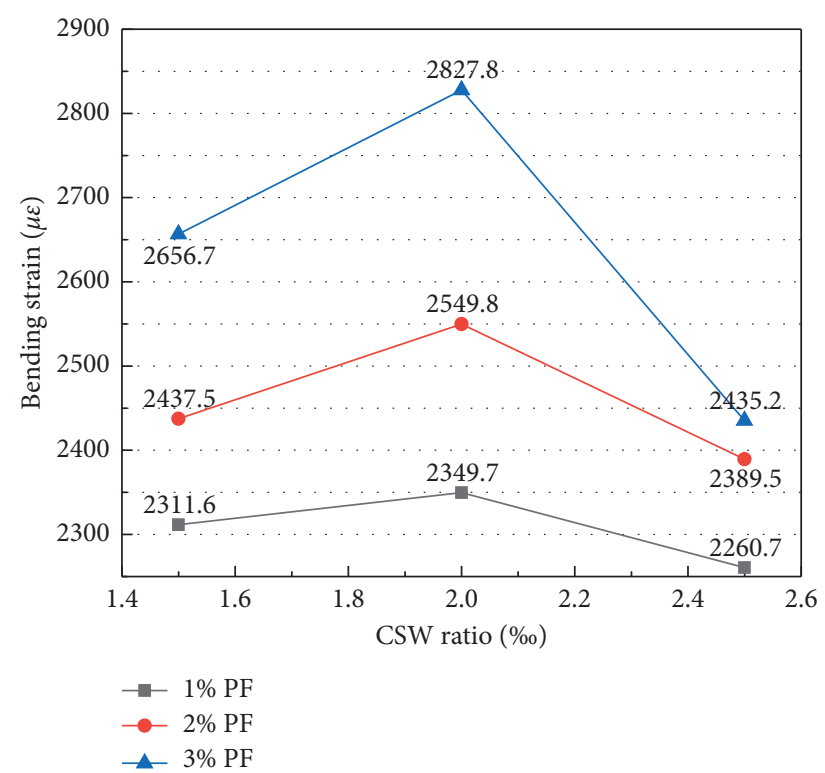

(a)

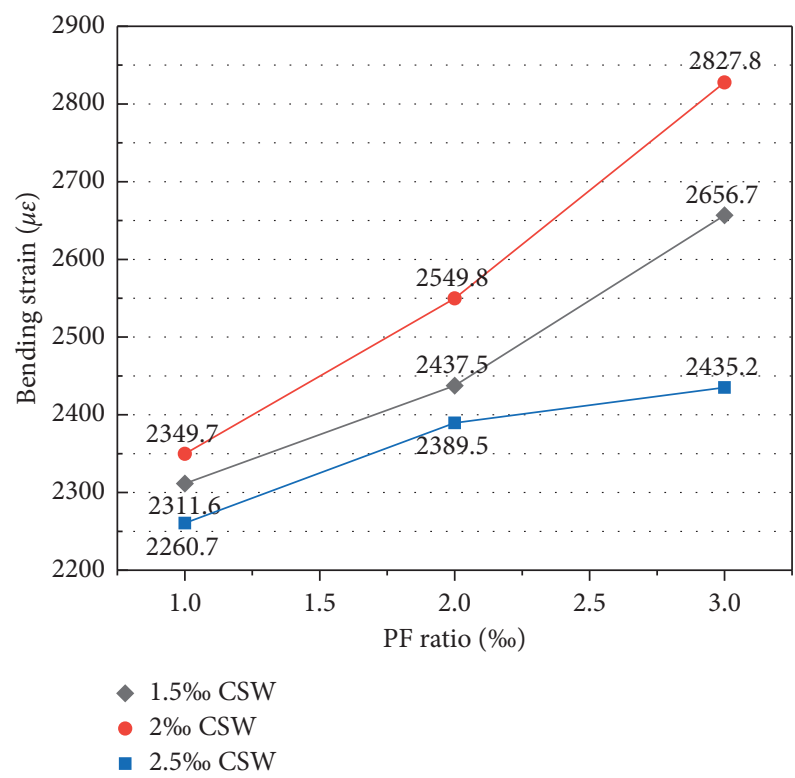

(b)

Figure 3: Bending test results. (a) Comparison of bending strain values for different calcium sulfate whisker rates and for certain polyester fiber amounts. (b) Comparison of bending strain values for different polyester fiber amounts and for certain calcium sulfate whisker rates.

\section{Conclusions}

Based on the road performance test of asphalt mixture, the paper studies the road performance difference of different contents of CSW-PF composite-modified asphalt mixture. The conclusions are as follows:

(1) Due to the good compatibility between CSW and asphalt, PF is not soluble in asphalt and easy to agglomerate, so composite technology (CSW wet process, polyester fiber dry process) should be used to mix the composite-modified asphalt mixture, and the modifier will be evenly distributed in the asphalt mixture

When CSW is in the range of $1.5 \%$ o $2.0 \%$, with the increase of CSW, the dynamic stability also increases. CSW has a positive effect on the high-temperature performance of asphalt mixture. Because of the agglomeration of the fiber, the high-temperature performance of the asphalt mixture over $2 \%$ polyester fiber becomes weak.

The water stability of composite-modified asphalt mixture is better than that of matrix asphalt mixture. CSW and PF have a positive effect on the water stability of mixture, but the degree of modification of CSW is far less than that of PF.

When the content of polyester fiber is $1 \% 0 \sim 2 \%$, it has a positive effect on the low-temperature performance of the mixture. The low-temperature ductility of asphalt is sensitive to the content of CSW. Excessive CSW will reduce the lowtemperature ductility of asphalt, so as to reduce the lowtemperature performance of the mixture. When the content of CSW is $1.5 \%$ $2 \%$, the low-temperature performance of the mixture is the best.

\section{Data Availability}

The corresponding author can provide the data produced by the study upon reasonable request.

\section{Conflicts of Interest}

The authors declare that they have no conflicts of interest regarding the publication of this paper.

\section{Acknowledgments}

This research was funded by the Basic Public Welfare Research Project of Zhejiang Province (LGF18E080015).

\section{References}

[1] C. F. Ai, X. D. Kuang, J. Chen, and Y. J. Qiu, "Influence of low temperature compaction on road performance of asphalt mixture," Journal of Highway and Transportation Research and Development, vol. 3, no. 2, pp. 29-33, 2008.

[2] Q. He, H. Q. Chen, J. Y. He et al., "Study on preparation process and aging performance of sbr-eps composite modified asphalt," Science and Technology and Engineering, vol. 19, pp. 315-320, 2019.

[3] J. Yang, "Research on anti-aging ability of polyphosphoric acid/SBR composite modified asphalt with high and low temperature performance," Journal of China \& Foreign Highway, vol. 39, pp. 249-254, 2019.

[4] Z. X. Zhong and P. Dong, "Research on the properties of reactive terpolymer composite modified asphalt and its mixture," New Building Materials, vol. 11, pp. 8-17, 2019.

[5] T. Fan, S. N. Lin, Y. M. Yin, and W. J. Hou, "Experimental study on polyurethane and rubber powder composite 
modified asphalt," New Building Materials, vol. 43, pp. 83-86, 2016.

[6] C. F. Zhu, Y. C. Chen, C. Y. Liang, and B. Xiao, "Road performance test of diatomite basalt fiber composite modified asphalt mixture," Journal of Jilin University (Engineering and Technology Edition), vol. 50, pp. 165-173, 2020.

[7] H. F. Hassan, S. Al-Oraimi, and R. Taha, "Evaluation of opengraded friction course mixtures containing cellulose fibers and styrene butadiene rubber polymer," Journal of Materials in Civil Engineering, vol. 17, no. 4, pp. 416-422, 2005.

[8] J. P. Serfass and J. Sammanos, "Fiber-modified asphalt concrete: characteristics, applications and behavior," Journal of the Association of Asphalt Paving Technologists, vol. 65, pp. 193-230, 1996.

[9] N. Morova, "Investigation of usability of basalt fibers in hot mix asphalt concrete," Construction and Building Materials, vol. 47, pp. 175-180, 2013.

[10] D. Wang, L. Wang, X. Gu, and G. Zhou, "Effect of basalt fiber on the asphalt binder and mastic at low temperature," Journal of Materials in Civil Engineering, vol. 25, no. 3, pp. 355-364, 2013.

[11] X. Gu, T. Xu, and F. Ni, "Rheological behavior of basalt fiber reinforced asphalt mastic," Journal of Wuhan University of Technology-Mater. Sci. Ed.vol. 29, no. 5, pp. 950-955, 2014.

[12] J. Y. Liang, "Study on the road performance of polyester fiber for asphalt mixture," Petroleum Asphalt, vol. 31, pp. 22-25+35, 2017.

[13] G. Dong, N. X. Zheng, and J. F. Wang, "Road performance of polyester fiber asphalt mortar and mixture," Science \& Technology Review, vol. 33, pp. 49-53, 2015.

[14] M. J. Huang and X. Y. Zhang, "Application of calcium sulfate whisker in road asphalt," Petroleum Asphalt, vol. 28, pp. 7072, 2014.

[15] H. G. Zhang, P. W. Hao, and X. S. Wang, "Indoor research of high-modulus asphalt concrete with the added calcium sulfate whisker," Applied Mechanics and Materials, vol. 94-96, pp. 90-94, 2011.

[16] X. Xing, J. Pei, R. Li, and X. Tan, "Effect and mechanism of calcium carbonate whisker on asphalt binder," Materials Research Express, vol. 6, pp. 1-19, 2019.

[17] X. S. Wang, "Road performance of calcium sulfate whisker high modulus asphalt concrete," Journal of Chongqing Jiaotong University (Natural Science), vol. 30, pp. 1331-1334, 2011.

[18] T. Fan, X. Wang, Y. Gao, and X. Zhang, "Investigating the interaction mechanism and effect of different calcium sulfate whiskers on performance of asphalt binder," Construction and Building Materials, vol. 224, pp. 515-533, 2019.

[19] T. Serkan, "The effect of polypropylene fibers on asphalt performance," Building and Environment, vol. 43, pp. 10651071, 2008. 